\title{
The yeast splicing factor Mud13p is a commitment complex component and corresponds to CBP20, the small subunit of the nuclear cap-binding complex
}

\author{
Hildur V. Colot, Françoise Stutz, and Michael Rosbash ${ }^{1}$ \\ Howard Hughes Medical Institute, Brandeis University, Department of Biology, Waltham, Massachusetts 02254 USA
}

\begin{abstract}
The mechanism by which pre-mRNAs are initially recognized by the splicing machinery is not well understood. In the yeast system, commitment complexes are the earliest identified splicing complexes. They contain pre-mRNA, U1 snRNP, and the splicing factor Mud2p and probably correspond to the mammalian E complexes, which contain pre-mRNA, U1 snRNP, and the splicing factor U2AF. To identify other yeast commitment complex components, we have characterized mutant strains that are synthetic lethal with viable U1 snRNA mutations. We report here that $M U D 13$ is a nonessential gene that encodes the yeast homolog of CBP20, the small subunit of the vertebrate nuclear cap-binding complex (CBC). Characterization of splicing in the $\triangle M U D 13$ strain and extract indicates that Mud13p is a yeast splicing factor and is the second identified non-snRNP commitment complex component. The observations also suggest that $C B C$ interacts with other commitment complex components as well as with the substrate cap. Taken together with the accompanying results for a mammalian system, our data indicate that cap-binding proteins as well as the pre-mRNA cap contribute to early steps in spliceosome assembly.
\end{abstract}

[Key Words: Splicing; CBP20; MUD13; Saccharomyces cerevisiae; Ul snRNP; cap binding]

Recejved January 21, 1996; accepted in revised form May 27, 1996.

In eukaryotes, much of gene expression is dependent on pre-mRNA splicing, the removal of intervening sequences (introns) from primary transcripts. The splicing pathways in yeast (Saccharomyces cerevisiae) and vertebrate systems are fundamentally the same and involve the same three cis-acting regions of the pre-mRNA substrate: the 5' splice site, the branchpoint, and the $3^{\prime}$ splice site. Covalent bond cleavage and ligation occur at these locations, and these regions also serve to recruit trans-acting factors to the substrate. These factors /proteins and small nuclear ribonucleoprotein particles / snRNPsil associate with the substrate to form the mature spliceosome within which splicing takes place (Rymond and Rosbash 1992; Moore et al. 19931.

In vitro spliceosome assembly is itself an ordered process, during which the four snRNPs, containing five snRNAs $\{U 1, U 2, U 5$, and $U 4 / 6\}$, associate with the premRNA substrate. The snRNAs are quite conserved between yeast and mammals (Guthrie 1991; Steitz 1992; Moore et al. 1993), and the order of addition is also conserved: First, U1 snRNP is added in an ATP-independent reaction, then $U 2$ snRNP (in an ATP-dependent reaction), followed by the U4/6/U5 tri-snRNP (Green 1991;

${ }^{1}$ Corresponding author.
Rymond and Rosbash 1992; Moore et ai. 1993). In the yeast system, the UI snRNP-containing complexes visible by gel electrophoresis are called commitment complexes because their formation appears to commit the pre-mRNA substrate stably to the splicing pathway (Séraphin and Rosbash 1989|. Commitment complex formation depends on RNA-RNA interactions, as basepairing takes place between the yeast $5^{\prime}$ splice site sequence (GUAUGU) and the highly conserved 5 ' end of yeast Ul snRNA (Rosbash and Seraphin 1991). Proteinprotein and protein-RNA interactions also contribute to complex formation; for example, the Mud2 protein is a component of the complete complex and associates with the pre-mRNA as well as with Ul snRNP (Abovich et al. 1994). The yeast Mud2 protein resembles the mammalian splicing factor U2AF65 (Zamore et al. 1992), thus extending the similarity between the two systems. In mammalian in vitro splicing, the $E$ (early\} complex is the first pre-spliceosome complex observed; like yeast commitment complexes, it forms in the absence of ATP and contains U1 snRNP (Michaud and Reed 1991). It also contains U2AF as well as other undefined proteins and is probably the functional equivalent of the yeast commitment complex (Bennett et al. 1992). There is little known about the identities or roles of other non-snRNP proteins in $\mathrm{E}$ complex formation. 
To identify yeast proteins that might be important for commitment complex formation, we designed a genetic strategy to identify snRNP as well as non-snRNP proteins that contribute directly to this process (Liao et al. 1993). We isolated mutants that were lethal in combination with viable Ul snRNA mutants. The synthetic lethal approach requires that the identified genes be inessential or that the mutants be caused by incomplete lossof-function mutations. In an attempt to discard those mutants that had indirect genetic interactions with the U1 snRNA mutations, we employed a biochemical subscreen: Extracts were prepared and in vitro commitment complex formation examined for quantitative or qualitative differences compared to extracts from wild-type strains. This strategy resulted in the identification of the gene MUD1, which encodes the yeast version of a wellstudied component of Ul snRNP, the UIA protein /Liao et al. 1993|. It also yielded the gene $M U D 2$, as described above (Abovich et al. 1994).

We now report the third splicing factor identified in this screen: MUD13 encodes the yeast homolog of CBP20, the small subunit of the mammalian nuclear cap-binding complex $(\mathrm{CBC})$. As yeast $\mathrm{CBC}$ had not been identified and there was no information on the contribution of the pre-mRNA cap to yeast splicing, this finding inspired a thorough characterization of the phenotypes of a MUD13 deletion strain, both in vitro and in vivo. The results identify Mudl3p as the second nonsnRNP component of the commitment complex. Taken together with the results of Lewis ct al. (this issuel, they indicate that the $\mathrm{CBC}$ is an important splicing factor that contributes to a very carly step in spliceosome assembly in both yeast and mammalian systems.

\section{Results}

\section{MUD13 is yeast CBP2O}

Like extracts from the well-characterized mudl and mud2 mutant strains, cxtracts from the mud13-1 strain manifested abnormal commitment complex formation (Liao et al. 1993; Abovich et al. 1994; see below). Because this suggested that MUD13 encoded a splicing factor involved in E complex formation, the gene was cloned by rescuing the lethal combination of mud13-1 and the mutant UI RNA with a genomic yeast library.

Sequence analysis predicted that MUD13 encodes a protein of 209 amino acids $(24 \mathrm{kD}$ ) with one classic RNA-binding domain (RBD). Although many RNA-binding proteins received high scores in a BLAST search by virtue of their similar RBDs, our initial searches revealed no certain relatives in the available data bases. However, human CBP20 was recently cloned and sequenced (Izaurralde et al. 1995; Kataoka et al. 19951, and visual inspection immediately revealed extensive conservation between it and Mud13p. The GAP alignment program indicatcd $73 \%$ similarity and $51 \%$ identity, with threc short gaps in an otherwise perfect alignment (Fig. 1). Mud $13 \mathrm{p}$ and hCBP20 are almost identical in the region encompassing the RNP2 and RNPl motifs. Extensive homology is also seen in the region corresponding to amino acids 125-155 of Mud I3p, which is rich in glycine and charged amino acids. However, the yeast sequence has 5.3 additional amino acids at its carboxyl terminus.

To support a case for functional as well as sequence homology between the two proteins, we undertook a two-hybrid assay, in which we checked for interactions of Mud13p with human CBP80 and its yeast homolog Stolp (Uemura and Jigami 1992; Izaurralde et al. 1994). Mud13p interacts with both proteins, but the interaction with human CBP80 is noticeably stronger (Fig. 2). (Western blots showed that the levels of expression of all these proteins were approximately equal; data not shown.) These data reinforce the contention that Mud13p is indecd yCBP20.

\section{In vivo phenotypes}

The cloned and sequenced DNA was used to generate a deletion strain. Like the original mud13-1 mutation, the deletion had only a mild effect on growth in normal medium, that is, the gene is inessential. To examine in vivo splicing, we compared the deletion and wild-type strains with intron-containing reporter genes requiring intron removal to generate copper resistance (Lesser and Guthrie 199.3; Table 11. The deletion background decreased the copper resistance of RP51A-CUP /containing the efficiently spliced wild-type RP51A intron/from $>1.7 \mathrm{~mm}$ to $1.2 \mathrm{~mm}$, suggesting a modest effect on gene expression. We also used two inefficiently spliced reporter genes: One contained the 5 ' splice site mutant RP51A5'II, and the other the short artificial mRNA coding $(\mathrm{MC})$ intron [Stutz and Rosbash 1994!. This strategy has been used previously to analyze strains that are splicing mutant candidates, as the inefficient substrates are sensitive to even slight decreases in splicing efficiency (Liao et al. 19931. Both reporter genes showed a moderate reduction in resistance in a wild-type strain background $(1.3 \mathrm{~mm}$ copperl. In the MUD13 delction strain, however, there

$$
\begin{aligned}
& \text { MUD13 } 1 \text { MSLEEEDEVKYDHSTKRLDTPSRYLLLRKARRNPNGLQELRESMRSS } 47 \\
& \text { hCBP } 20 \quad 1 \text { MSGGLLKALRSDSYVELSOYRDQHF . . . . R RGDNEEQE KLLKKSC } 40 \\
& 48 \text { TIYYGNLSFYTSEEQ IYELFSKCGT IKR I IMGLDRFKFTPCGFCF IIYSCPDE } 100 \\
& \begin{array}{l}
41 \text { TLYVGNLSFYTTEEQIYELFSKSGDIKKIIMGLDKMRKTACGFCFVEYYSRAD } 93 \\
\text { RNP2 }
\end{array} \\
& 101 \text { ALNALKYLSYTKLDEKTITIDLDPGFEDGRQFGRGKSGGQVSDELRFDFD } 150 \\
& 94 \text { AENAMRYINGTRLDDRIIRTDWDAGFKEGRQYGRGRSGGQVRDEYRQDYD } 143 \\
& 151 \text { ASRGGFAIPFAERVGVPHSRFDNSSSQSNTNNYIPPPDAMGTFRPGFDEE } 200 \\
& 144 \text { AGRGGYG. KLAQNQ } \\
& 201 \text { REDDNYVPQ }
\end{aligned}
$$

Figure 1. Sequence comparison of MUD13 and human CBP20. The predicted MUD13 (top) and human CBP20 (hCBP20, bottom! sequences were compared by the Genetics Computer Group \&GCG) program Gap. The conserved RNP2 and RNP1 motits are underlined. Identical and similar residues are indicated by vertical lines and dots, resnectively. The program calculated $7.3 .1 \%$ similarity and $50.6 \%$ identity between the two scquences. 


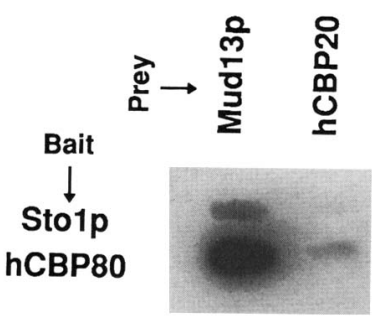

Figure 2. Two-hybrid interactions of yeast and human capbinding proteins. The interactions of the indicated combinations of bait-prcy fusion proteins were analyzed in diploids using a mating assay and growth on selective X-gal indicator plates isec Materials and methods|. STOl is the yeast cquivalent of $\mathrm{hCBP} 80$ and $M U D 13$ is yeast CBP2O.

was severely reduced copper resistance for both of these introns $(<0.2$ and $0.3 \mathrm{~mm}$ copper, respectively).

To test whether the reduced copper resistance actually reflected a defect at the mRNA level, we performed primer extension analysis of total RNA from these strains (Fig. 3). The pre-mRNA to mRNA ratios (P/M) for the $\mathrm{MC}$ and $5^{\prime} \mathrm{II}$ introns are twofold and sixfold higher in the deletion strain, respectively, consistent with a decrease in splicing efficiency (Pikiclny and Kosbash 1985). More significantly, these two reporter genes manifested a dramatic reduction in mRNA levels (Fig. 3). Because the three reporter genes are identical except for intron sequences, only differences in splicing between the wildtype and MUD13 deletion strains can easily account for the observed differences in mRNA levels. There is also a less pronounced decrease in pre-mRNA levels, which probably reflects an additional effect of the MUD13 deletion at the level of RNA turnover (see Discussion).

\section{In vitro phenotype: capped substrate}

The mud13-1 strain was originally chosen for further study because of its in vitro phenotype. Extracts made

Table 1. Copper resistance of wild-type and $\triangle$ MUD 13 copper-sensitive strains expressing intron-containing CUPl reporter constructs

\begin{tabular}{|c|c|c|c|}
\hline & RP51A-CUP & RPSIA5'JI-CUP & $M C-C U P$ \\
\hline WT $\triangle C U P$ & $>1.7$ & 1.3 & 1.3 \\
\hline \multirow[t]{2}{*}{$\triangle M U D 13 \triangle C U P$} & 1.2 & $<0.2$ & 0.3 \\
\hline & & $\mathrm{Cu}^{++}(\mathrm{mM})$ & \\
\hline
\end{tabular}

In the RP51A-CUP or RP51A5'II-CUP constructs, the wildtype or 5 ' splice site mutant (CUAUGU $\rightarrow$ GUAUaUl RP51A intron (Teem and Rosbash 1983) was cloned into the 5' end of the CUP1 sequence, respectively. In the MC-CUP construct, the CUP1 gene is interrupted by a small artificial intron (Legrain and Roshash 1989). In all three constructs, only the spliced mRNA is in-frame with the CUP1 coding sequence. The levels of spliced transcripts were assaycd by growth of the strains on selective plates containing increasing concentrations of copper. The numbers indicate the highest copper concentration (m.M) on which each transformed strain can grow.


Figure 3. Primer extension analysis of CUPI reporter RNA levels in vivo. Total RNA was extracted from wild-type (lanes 1.3.5\} or 1 MUD I.3 strains \{lanes 2,4,6\} expressing the RP51 ACUP ilanes 1,21, RP5l A. II-CUP ilanes 3.4) or MC-CUP ilanes 5.61 reporter constructs. The RNAs were reverse transcribed with a primer complementary to the CUP1 RNA sequence. A primer specific for U2 SnRNA was added to the reactions as an internal control. The primer-extended bands corresponding to CUP 1 pre-mRNA $(P)$, mRNA $|\mathrm{M}|$, and $\mathrm{U} 2$ are indicated.

from this strain, which harbors the mutant U1 snRNA used in the genetic screen, give commitment complex bands with an altered mobility (data not shown). The MUD13 deletion strain also shows the original in vitro phenotype (Fig. 4): With a wild-type Ul snRNA, commitment complexes show the same decreased mobility. In addition, there is a large reduction in the level of complexes.

It is possible that the in vitro commitment complex phenotype of the deletion strain is attributable only indirectly to the absence of the Mud13 protein rather than 


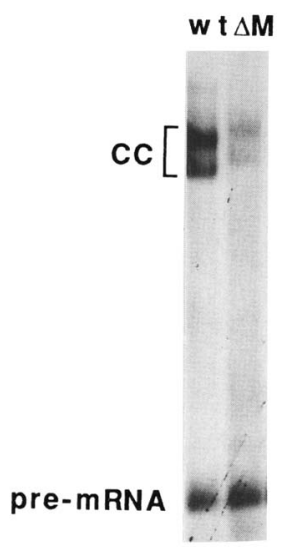

Figure 4. Commitment complex formation in wild-type and MUD13 deletion extracts. Capped, labeled substrate was synthesized in an in vitro transcription reaction. The labeled RNAs were incubated with either wild-type (wt) or MUD13 deletion extract $(\Delta M)$ under standard conditions for commitment complex formation and analyzed on a native gel |see Materials and methods $\mid$. Commitment complexes $|\mathrm{CC}\rangle$ and tree pre-mRNA are indicated

reflecting a direct contribution to commitment complex formation. To verify that Mud13p participates directly, we purified a recombinant Mudl3p-glutathione $S$-transferase $[\mathrm{GST}\rangle$ protein from Escherichia coli and added it to the deletion strain extract. The protein effected robust rescue of commitment complex formation that was dependent on the amount of added recombinant Mud $13 \mathrm{p}-$ GST, but complex mobility was poorly rescued (Fig. 5A; data not shown). The recombinant protein not only stimulates complex formation but is also a commitment complex component: The complexes were supershifted/ dissociated with an anti-GST antibody, which required prior addition of the fusion protein to the extract (Fig. $5 \mathrm{~A})$. A further indication that Mud $13 \mathrm{p}$ is a complex component is provided by the mobility of the complexes rescued by the recombinant fusion protein cleaved with thrombin, which separates the GST and Mudl3p moieties. Addition of the cleaved protein resulted in complexes with mobilities that more closely resembled those of wild-type complexes, compared with the slower complexes obtained with the intact fusion protein (Fig.

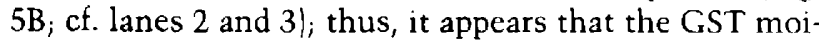
ety in the uncleaved protein is largely responsible for its failure to rescue the mobility phenotype. We conclude that CBP20 makes a direct, potent contribution to commitment complex formation and that it is a commitment complex component.

Splicing was also reduced in the deletion strain extract compared with wild type (e.g., Fig. 6B), consistent with the abundant evidence indicating that UI snRNP and commitment complex formation are necessary for the first step of yeast splicing (Séraphin and Rosbash 1989, 1991; Rosbash and Séraphin 1991). However, recombinant Mud13p-GST was unable to effect substantial rescue of the reduced splicing under conditions in which commitment complex rescue was potent (data not shown. We assume that this failure reflects some feature of Mudl3p that is lacking in the E. coli-derived protein or some additional defect of the mutant extract. However, it is also possible that the MUD13 deletion has little or no effect on in vitro splicing, that is, the effect on commitment complex formation may not be rate limiting for in vitro splicing under these conditions isee below).

\section{In vitro phenotypes: uncapped substrate}

Because of the effects on commitment complex formation as well as the described interaction between CBC
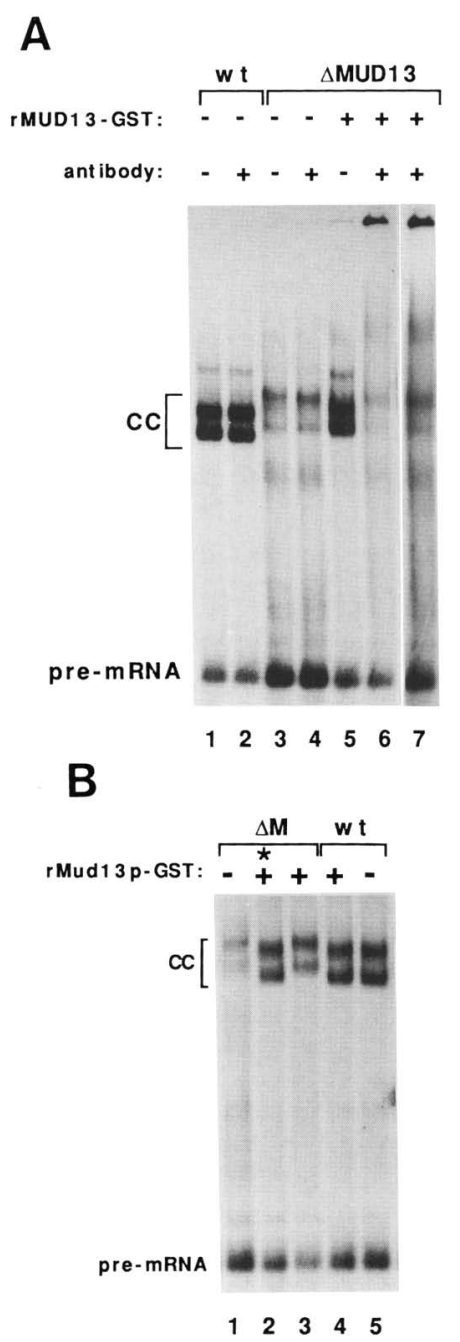

Figure 5. Rescue and supershift of commitment complexes with an IMud13p-GST fusion protein. Labeled, capped premRNA was incubated with wild-type (wt) or MUD13 deletion (DM) extract, as in Fig. 4. (A) rMudl3p-GST and/or anti-GST antibody were added to some reactions, as indicated above the lanes (see Materials and methods). Lane 7 is a longer exposure of lane $6 .\{B \mid$ rMud $13 \mathrm{p}-\mathrm{GST}$ was added to some reactions, either before (lanes 3.4 ) or after $\left({ }^{\circ}\right.$, lane 2 ) cleavage by thrombin (see Materials and methods.. Commitment complexes $(\mathrm{CC})$ and free pre-mRNA are indicated. 
A

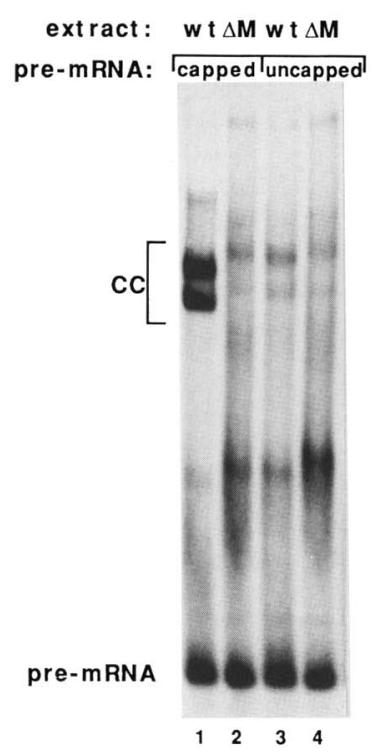

B

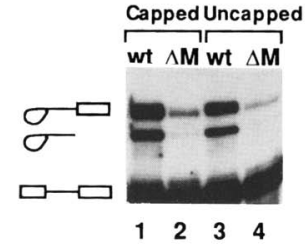

Figure 6. Commitment complex formation and splicing with an uncapped pre-mRNA. (A) Capped or uncapped labeled premRNA was incubated in a wild-type (wt) or MUD)13 deletion $(\Delta M)$ extract under standard commitment complex conditions and analyzed on a native gel. Commitment complexes $\mid \mathrm{CCl}$ and free pre-mRNA are indicated. $|B|$ The substrates were incubated with either wild-type $\mid w t\}$ or MUD13 deletion $(د \mathrm{M})$ extract, and the products analyzed on a $15 \%$ polyacrylamide denaturing gel. Pre-mRNA, lariat intermediate, and lariat are indicated schematically. As is evident here, some degradation often occurs with the uncapped substrate during the reaction, but the splic. ing efficiency (lariat intermediate plus lariat as a percent of totall is the same for capped and uncapped substrates in each extract.

and capped RNAs in mammalian systems, we also compared commitment complexes formed on capped and uncapped substrates. The cap has a major impact on the levels of complexes (Fig. 6A). In this assay, the uncapped substrate phenocopies the mutant extract, qualitatively as well as quantitatively, suggesting (1) that the mobility differences between complexes with capped and uncapped pre-mRNAs reflect the presence and absence of $\mathrm{CBC}$, respectively; and $\{2 \mid$ that there are substantial effects of the cap on complex formation or stability.

To our surprise, splicing was indistinguishable from that seen with the cognate standard capped substrate. This is the case in the MUD13 delction strain as well as in the wild-type strain (Fig. $6 \mathrm{~B}$ ), indicating that in vitro splicing of both substrates is similarly affected by the MUD 13 deletion. As discussed above, the failure to rescue splicing with the recombinant protein may indicate that the absence of CBP20 has no substantial effect on the in vitro splicing rate of either substrate. The similar splicing of the capped and uncapped substrates indicates that the cap effect on commitment complexes is likely to be on complex stability rather than complex formation.

To verify that the uncapped substrate interacts with Ul snRNP in a manner that resembles the capped substrate-U1 snRNP interaction, splicing of both substrates was analyzed after preincubation of a wild-type extract with a 2'-O-methyl oligonucleotide complementary to the 5 ' end (10 nucleotides) of UI snRNA. UI snRNP inactivation has a dramatic effect on the splicing of both substrates (Fig. 7A). Spliceosome formation was similarly affected (data not shown). A second assay consisted of a commitment complex chase experiment. Both substrates were incubated in extract depleted of ATP, fol-
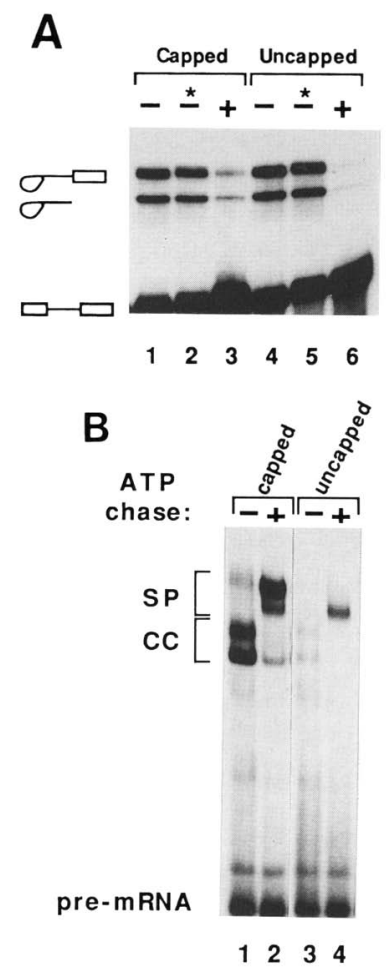

Figure 7. $|A| \mathrm{Ul}$ snRNP dependence of splicing of an uncapped substratc. A wild-type extract was preincubated with $|+|$ or without $1 \dot{-1}$ a $2^{\circ}$-O-methyl oligonucleotide complementary to the 5 ' end of U1 snRNA [see Materials and methods]. Labeled pre-mRNA was then added. For lanes 1 and 4 , reactions were performed as usual, without preincubation $(-1)(B)$ Chase of commitment complexes formed with uncapped substrate. Commitment complexes were formed after depleting the extracts of ATP (lanes 1.3), followed by the addition of an excess of cold pre-mRNA and ATP (lanes 2,4) to chase preformed commitment complexes $|\mathrm{CC}|$ into spliceosomes $|\mathrm{SP}\rangle$ |sce Materials and methodsl. 
lowed by the addition of an excess of cold pre-mRNA and ATP to chase preformed U1 snRNP complexes into spliceosomes (Legrain et al. 1988). The levels of pre-chase commitment complexes and post-chase spliccosomes loperationally defined as U2 snRNP-containing complexes) were compared (Fig. 7B).

The capped substrate shows similar levels of commitment complexes and spliceosomes. In contrast, the uncapped pre-mRNA substrate shows substantially higher levels of spliceosomes than of commitment complexes. This indicates that Ul snRNP complexes were poorly detected by gel electrophoresis. It is also apparent that the spliceosomes formed with the capped and uncapped substrates are different, quantitatively and qualitatively: The latter have lower levels and consist primarily of the lower band, which contains U2 snRNP but not U1 snRNP. (The upper band contains both snRNPs; data not shown.! The observation further supports the contention that the interaction between Ul snRNP and the uncapped pre-mRNA is relatively unstable, and this is despite the fact that spliced product levels in such a chase are identical for both substrates (data not shown). Taken together, the data indicate that commitment complex formation (the pre-mRNA-Ul snRNP interaction) is similar for uncapped and capped substrates, but the uncapped complexes are relatively unstable.

All of these in vivo and in vitro observations can be accommodated in a simple model: The absence of the substrate cap or CBP20 affects complex stability and splicing, but the remaining interactions are strong enough to minimize effects on the rate or extent of in vitro splicing with an efficient substrate. Therefore, the absence of the substrate cap or CBP20 weakens but does not eliminate the network of interactions among the remaining commitment complex components, for example, CBP80, the pre-mRNA substrate, Ul snRNP, Mud2p, and so on. The potent effect on the commitment complex assay indicates that CBP2O must contribute to the pre-mRNA substrate-UI snRNP interaction, that is, it must interact with other commitment complex components as well as with the substrate cap (Fig. 8). This suggests that the synthetic lethality originally observed might reflect direct as well as indirect interactions between CBP20 and U1 snRNP.

\section{Discussion}

We identified mud13-1 as onc of several mutants that arc synthetically lethal with viable Ul snRNA mutants. There is little doubt that MUD13 encodes the yeast version of CBP20, the small subunit of the nuclear CBC: $\mid 1$ ) The sequence conservation with metazoan CBP20 (Izaurralde et al. 1995) is impressive and unique; (2) yCBP20 interacts with hCBP80 in a yeast two-hybrid assay (Fig. 2); (3) the yeast CBP20 gene was independently cloned by D. Gorlich, E. Izaurralde, E. Hartmann, R. Kraft, S. Kostka, F. Vogel, R.A. Laskey, and I.W. Mattai (in prep.l, who showed that it copurifies in a tighe complex with yCBP80, the product of the STO1 gene; (4) purified $\mathrm{yCBC}$ or recombinant $\mathrm{yCBC}$ (a mixture of recombinant

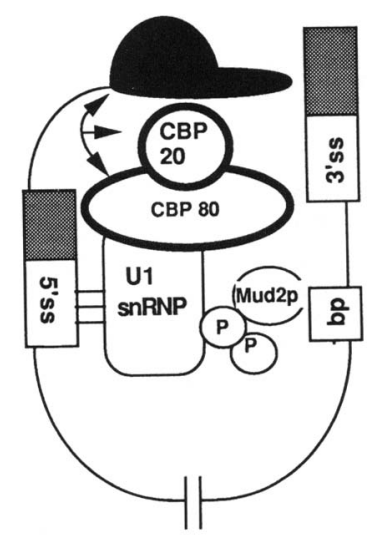

Figure 8. Model of commitment complex. The major players, as depicted, are the $5^{\prime}$ splice site $\left\{5^{\prime} \mathrm{ss} \mid\right.$ and branchpoint $|\mathrm{bp}|$ sequences of the pre-mRNA; Ul snRNP (in rounded box); Mud2p; several unidentified proteins (circled $\mathrm{P}$ ); the pre-mRNA cap |drawn as a baseball capl; and the cap-binding complex $|C B C|$, consisting of CBP20 and CBP80. The three arrows represent primary interactions of the $C B C$ with the pre-mRNA cap. The contact between CBP 80 and $U 1$ snRNP reflects the inferred interaction between $\mathrm{CBC}$ and other commitment complex components.

yCBP20 and yCBP80) binds to capped RNA (D. Gorlich, E. Izaurralde, E. Hartmann, R. Kraft, S. Kostka, F. Vogel, R.A. Laskey, and I.W. Mattaj, in prep.); and (5) characterization of commitment complex formation from the deletion strain (Figs. 4, 5, and 6A) shows that there are striking similarities to complexes formed in CBC-depleted mammalian extracts (Lewis et al., this issue).

It is difficult to speculate on the possible significance of the sequence differences between mammalian and yeast CBP20. However, these may reflect functional differences between yeast and mammalian CBC. For example, we have been unable to inhibit complex formation and splicing by the addition of cap analogs, even at concentrations 100 -fold greater than those reported to be effective in mammalian extracts (Konarska et al. 1984; data not shown). Also, commitment complexes form equally well on substrates containing different caps /GpppG and $m 7 \mathrm{GpppG}$; data not shown/. Finally, the yCBC discriminates less well than the hCBC among some cap analogs (D. Gorlich, E. Izaurralde, E. Hartmann, R. Kraft, S. Kostka, F. Vogel, R.A. Laskey, and I.W. Mattai, in prep.). All three of these observations suggest that the binding of $y C B C$ to capped RNA may be more dependent on other features of the substrate RNA sequence or on additional protein factors. It is possible that the unique carboxy-terminal portion of yCBP20 is relevant to these differences.

There is substantial cvidence from vertebrate systems that the pre-mRNA cap and $\mathrm{CBC}$ contribute to splicing [Izaurralde et al. 1994]. An effect of the yeast pre-mRNA cap on splicing is also supported by very recent in vivo studies using temperature-sensitive capping mutants (Fresco and Buratowski 1996; Schwer and Shuman 1996). It is therefore not surprising that yeast strains missing 
Mud13p manifest effects on pre-mRNA splicing efficiency. These effects are also consistent with the synthetic lethality of mud13-1 with U1 snRNA mutations. The MUD13 deletion is also synthetic lethal with a deletion of the MUD2 gene, indicating an interaction with at least one other commitment complex component (Abovich et al. 1994).

However, the effects on in vivo splicing are weak. There is only a twofold reduction in mRNA levels from an efficiently spliced wild-type intron. This is an overestimate of the deletion effect on splicing of an efficient intron, because a similar effect on gene expression was observed with a cDNA version of the same gene (data not shown|. The effect on in vivo splicing efficiency by the MUD13 deletion is not surprising given the strain's fairly robust growth. These modest effects on splicing and growth may also reflect the fact that the strain still contains substantial levels of yCBP80 [1. Mattai, pers. comm.), that is, the cells may contain residual CBC activity provided by the CBP80 subunit. Consistent with this notion is the fact that the comparable STOI deletion strain grows morc poorly and contains no detectable CBP2O in addition to no detectable CBP8O (data not shown; I. Mattaj, pers. comm.). (Presumably, in the absence of CBP80, CBP20 is unstable in vivo.) The fact that neither Mud13p/CBP20 nor CBP80 is essential for splicing in yeast or in mammalian extracts (Lewis et al., this issuel is consistent with the view that these proteins, as well as other well conserved splicing factors that we have characterized (Liao et al. 1993; Abovich et al. 1994), make quantitative rather than qualitative contributions to splicing.

Yet the two genes with poorly spliced introns generate very low levels of mRNA. It is intriguing that the RP51A5'II (5' splice site mutant) intron substrate is affected the most severely, as assayed by both copper resistance and primer extension (Table 1 and Fig. 3, respectivelyl. This is consistent with the formation of an interaction between the $5^{\prime}$ splice site, Ul snRNP, and $\mathrm{CBC}$, as suggested by the in vitro results (Figs. 4, 5, and 6). The primer extension results also show consistent decreases in pre-mRNA levels, suggesting that the failure to assemble proper CBC-RNA complexes may have additional consequences, for example, on RNA stability. This observation emphasizes the difficulty in proving that a protein impacts directly on splicing based solely on in vivo splicing assays in mutant strains.

However, the in vitro experiments show that Mudl $3 p$ makes a potent contribution to commitment complex formation and is a commitment complex component. This is based on three independent arguments: the rescue of commitment complex formation with recombinant Mud 13p-GST |Fig. 5A), the effects of an anti-GST antibody (Fig. 5A), and the obscrved mobility shift caused by proteolytic cleavage between the GST and Mud13p domains (Fig. 5B). It is likely that Mud13p is complementing the other CBC component (yCBP80), which is present in the MUD13 deletion extract (I. Mattaj, pers. comm.).

The deletion strain native gel profile is phenocopicd by the addition of an uncapped substrate to a wild-type extract (Fig. 6Al. This result provides evidence that the pre-mRNA cap as well as CBC contributes to the commitment complex (Fig. 8). Remarkably similar conclusions for $\mathrm{CBC}$ and mammalian splicing have been reached independently by Lewis et al. (this issue). Their results with cross-linking between Ul snRNA and a substrate 5 ' splice site are virtually identical to our commitment complex assay results.

An enigmatic aspect of the data is that commitment complex mobility of the deletion strain is decreased relative to that of the wild-type strain (e.g., Fig. 4). This is the opposite of the more straightforward observation from the MUD2 and MUDI deletion strain extracts, in which the absence of a protein results in an increased mobility of one or both commitment complexes, respectively (Liao et al. 1993; Abovich et al. 1994). The decreased mobility in the MUD 13 deletion strain suggests that the addition of CBC causes a substantial conformaticnal rearrangement and/or the destabilization of other components.

A second enigma is that we have been unable to effect potent rescuc of splicing in the deletion extract with recombinant Mudl3p-GST (data not shown). As the same protein preparation rescues commitment complex formation well (Fig. 5A), this failure cannot be a trivial consequence of the protein preparation. The cleaved recombinant protein (Fig. $5 \mathrm{~B}$ ) and recombinant yCBP20 trom other sources also afford only very modest increases in splicing activity (data not shown), much less than that observed for commitment complex activity. These negative results may indicate that some aspect of the ycast protein (e.g., a post-translational modification) is unnecessary for in vitro commitment complex formation but required for the complexes to undergo progression to the catalytic steps of splicing. Alternatively, higher protein concentrations may be required to rescue splicing, perhaps because of specific aspects of the commitment complex assay, such as U2 snRNP inactivation. A third possibility is that the splicing decrease of the mutant extracts is only an indirect consequence of the MUD 13 deletion, that is, yCBP20 makes no essential in vitro contribution to splicing efficiency. Although similar effects on splicing as well as commitment complex formation have been observed in a STO1-deletion strain (CBP80 knockout), the quantitative effects in the mutant strains have been variable (data not shown). Because of these results, together with the failure to potentiate in vitro splicing of the mutant extract with the recombinant protein, we cannot connect CBP2O or the substrate cap to the rate or extent of in vitro splicing.

However, previous experiments have demonstrated a solid link between commitment complexes and splicing Sćraphin and Rosbash 1989, 1991; Rosbash and Séraphin 19911. Also, immunodepletion and add-back experiments with wild-type yeast extract and CBC affect commitment complexes and splicing in parallel (J. Lewis and 1. Mattaj, pers. comm.). These observations, taken together with the genetics, the effects on in vivo splicing, the effect of temperature-sensitive capping mutants 
(Fresco and Buratowski 1996; Schwer and Shuman 1996), the primary sequence conservation, and the effects of CBC on pre-mRNA-U1 snRNP interactions in a mammalian system (see Lewis et al., this issue), make it almost certain that the commitment complex rescue with recombinant Mud $13 \mathrm{p}$ is splicing related.

Given the evidence from vertebrate systems that a nascent transcript is capped after reaching a length of 20 30 nucleotides (Rasmussen and Lis 1993), CBC may be the earliest yeast splicing factor that contributes to both pre-mRNA recognition and the Ul snRNP-5' splice site interaction. An important interaction between the cap and the $5^{\prime}$ splice site may also be related to idiosyncratic features of yeast splicing: Yeast intron-containing genes almost always contain single introns, the introns are almost always at the 5 ' end of transcripts, and yeast splicing efficiency decreases markedly as the intron is moved toward the 3' end of the transcript (Rymond and Rosbash 1992). The availability of viable deletion strains for yCBC should allow us to test whether any of these features are related to the function of the cap or of $\mathrm{CBC}$.

\section{Materials and methods}

Cloning and deletion of the wild-type MUD13 gene

The original mud13-1 strain (Ym543) was used as the host for transformation with a wild-type yeast library based on the LEU2-CEN vector p366, as described (Liao et al. 19931. After subcloning, a $2.1-\mathrm{kb}$ HindIII-HindllI fragment capable of rescuing the mutation was identified. The MUD13 open reading frame was identified by linker insertion mutagenesis (Legrain et al. 1991/ and sequenced. To generate the deletion strain, a plasmid was constructed in which an XmnI-SnaBI fragment jen. compassing amino acids 53-207), was replaced by an EcoRI$B a m H I A D E 2$ fragment. An AfllII-Accl linear fragment from the resulting plasmid was transformed into strain Y59 |mata, leu2-3, leu2-112, ura3-52, $\operatorname{trp} 1-289$, arg4, ade2) for the gene disruption. Chromosomal deletion of the MUD13 gene was con. firmed by PCR analysis and Southern blotting of the genomic DNA.

\section{Two-hybrid cloning and mating assay}

The CBP80 and STO1 LexA fusion bait constructs were ob. tained by cloning the complete coding sequence of CBP80 |Izaurralde et al. 1994) as an EcoRI-SalI PCR fragment or the com. plete coding sequence of STOI (Izaurralde et al. 1994 and references therein) as a Sall PCR fragment into pEG202 + PL [HIS3/ $2 \mu \mathrm{m}$ ) cut with EcoRI-Sall or with Sall, respectively (Ruden et al. 1991; Gyuris et al. 19931. The PCR primers used for CBP80 PCR amplification were OFS5.3 and OFS54, and the primers used for STO1 amplification were OFS57 and OFS56. The yCBP20 and hCBP20 prey constructs were obtained by cloning the complete coding sequence of either yCBP2O as an EcoRISalI PCR fragment or hCBP20 as an EcoRI-Xhol PCR fragment

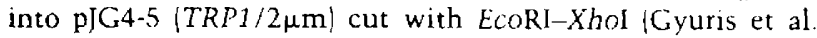
19931. The PCR primers for yCBP20 were OFS 58 and OHV 58 , and the primers for hCBP20 were OFS66 and OFS67. The bait and the prey constructs were transformed into strains RFY206 and EGY48, respectively (Finley and Brent 1994). The two-hy. brid interactions between the bait and prey fusion protens were determined using a mating assay and X-gal indicator plates as described previously (Finley and Brent 1994; Stutz et al. 19951.

\section{CUPl reporter plasmids and copper growth assay}

The MC-CUP reporter plasmid (LEU2/ $2 \mu \mathrm{m} /$ containung a small artificial intron was derived from plasmid pGIMC-CUP (TRP1) $2 \mu \mathrm{m}$ ) described previously (Stutz and Rusbash 1994). Briefly, the CUP1 transcription unit of $\mathrm{pGIMC-CUP}$ was excised with HindlII and XhaI and recloned into the unique BamHI site of PIH2 $\{$ LEU $/ 2 \mu \mathrm{m} \mid$ using BglI linkers. The RP51A-CUP and RP5IA5'II-CUP reporter plasmids $(L E U 2 / 2 \mu \mathrm{m})$ were obtained by replacing the BamHl-Smal intron tragment of MC-CUP with a BamHI-Smal PCR fragment amplifsed either from the wild-type [Teem and Rosbash 198.3) or the 5' II mutant RP51A introns ilacquier et al. 19851 using primers DT 2665 and DT 2540 . The CUP1 reporter plasmids were transformed (Ito et al. 19831 into copper-sensituve versions of the wild-type Y59 or the JMUD1.3 strains (Stutz and Rosbash 1994). The transformants were grown to saturation and spotted on Leu plates containing increasing concentrations of $\mathrm{CuSO}_{4}$; the copper resistance was determined atter 5 days of growth at $30^{\circ} \mathrm{C}$.

\section{RNA extractions and primer extensions}

RNA extractions and primer extensions were carried out according to published procedures (Pikiclny and Rosbash 1985) using two oligonucleotide primers. Oligonucleotide DT2965 is complementary to positions 29-51 downstream of the ATG of the CUPI gene (Karin et al. I984). Oligonucleotide DT2.371 is complementary to positions $30-46$ of U2 snRNA and was used as an internal control for loading. Extension products were analyzed on 6 "' polyacrylamide denaturing gels. The extended products were quantified using a Bio-Rad Molecular Imager or a Molecular Dynamies Phosphorlmager.

In vitro complexes and splicing

Splicing extracts were prepared essentially as described [Umen and Guthre ly951. U2 snRNP depletion for commitment complex formation was as described (Liao et al. 1992). All complexes werc formed with the $د 2$ substrate and analyzed on native gels, as described (Seraphin and Rosbash 1989). For the analysis of spliced products, aliquots of the reactions were removed at various times, phenol-extracted, ethanol-precipitated, and separated on $15 \%$ denaturing polyacrylamide gels. Ul snRNP inactivation was achieved with a $2^{\circ}-O$-methyl oligonucleotide complementary to 10 nucleotides of the $5^{\prime}$ arm of U1 snRNA. The oligonucleotide was preincubated at $0.1 \mathrm{pmol} / \mu \mathrm{l}$ with the complete reaction mixture lacking substrate. After $15 \mathrm{~min}$ at $25^{\circ} \mathrm{C}$, substrate was added and incubation continued for $30 \mathrm{~min}$. For the commitment complex chase experiments, ATP was tirst depleted by incubation of the extract in the presence of splicing salts, $1 \mathrm{~m} . \mathrm{y}$ glucose, and hexokinase at $0.5 \mathrm{U} / \mu \mathrm{l}$. Labeled substrate was added, and incubation continued for $20 \mathrm{~min}$. An aliquot was removed tor analysis, and the remainder chased by the simultaneous addition of excess cold pre-mRNA to $10 \mathrm{ng} / \mu \mathrm{l}$ and ATP to 5 m.M. Quantitation of all samples was performed on a Bio-Rad Molecular lmager.

\section{rMud1.3p-GST fusion protein}

A Mud1.3p-GST fusion construct was made by cloning the MUD13 coding sequence as an ECoRI-Sall PCR fragment into the vector pCiEX 4T-1 (Pharmacia) cut with EcoRI and Xhol. The construct was introduced into $E$. coli BL21 (DE 3) cells (Novagenl, and the recombinant fusion protein rMud1.3p-GST produced according to the manufacturer's directions. After purification on a glutathione-Sepharose column (Pharmacia), the re- 
combinant protein was dialyzed against buffer D (Newman et al. 19851, and 100-500 ng was added directly to the $5 \mu \mathrm{l}$ in vitro reactions at the outset. For some experiments, the fusion protein was cleaved by adding 2 units of thrombin (Pharmacial directly to $25 \mu \mathrm{g}$ of dialyzed protein and incubating overnight at room temperature. This mixture was added directly to the in vitro reaction. To supershift the complexes, $5 \mu \mathrm{g}$ of a polyclonal anti-GST antibody (Pharmacia) that had been affinity purified was added to the reactions after $10 \mathrm{~min}$ and incubation was continued for an additional $5 \mathrm{~min}$.

\section{Acknowledgments}

We thank Bertrand Séraphin, Bruno Charpentier, and Nadja Abovich for comments on the manuscript; Iain Mattaj, Eliza Izaurralde, Joe Lewis, Beate Schwer, Stewart Shuman, Lucille Fresco, and Stephen Buratowski for sharing unpublished information and helpful suggestions; and Lise-Anne Monaghan for help in preparation of the manuscript. This work was supported in part by a grant from the National Institutes of Health to M.R. (GM23549).

The publication costs of this article were defrayed in part by payment of page charges. This article must therefore be hereby marked "advertisement" in accordance with 18 USC section 1734 solely to indicate this fact.

\section{References}

Abovich, N., X.C. Liao, and M. Rosbash. 1994. The yeast MUD2 protein: An interaction with PRP1l defines a bridge between commitment complexes and U2 snRNP addition. Genes \& Dev. 8: 843-854.

Bennett, M., S. Michaud, J. Kingston, and R. Reed. 1992. Protein components specifically associated with prespliceosome and spliceosome complexes. Genes \& Dev. 6: 1986-2000.

Finley, R.L. and R. Brent. 1994. Interaction mating reveals binary and ternary connections between Drosophila cell cycle regulators. Proc. Natl. Acad. Sci. 91: 12980-12984.

Fresco, L.D. and S. Buratowski. 1996. Conditional mutants of the yeast mRNA capping enzyme demonstrate that the cap enhances, but is not required for, mRNA splicing. RNA (in press).

Green, M.R. 1991. Biochemical mechanisms of constitutive and regulated pre-mRNA splicing. Annu. Rev. Cell Biol. 7: 559599.

Guthrie, C. 1991. Messenger RNA splicing in yeast: Clues to why the spliceosome is a ribonucleoprotein. Science 253: $157-163$.

Gyuris, J., E. Golemis, H. Chertkov, and R. Brent. 1993. Cdil, a human Gl and S phase protein phosphatase that associates with Cdk2. Cell 75: 791-803.

Ito, H., Y. Fukuda, K. Murata, and A. Kimura. 1983. Transformation of intact yeast cells treated with alkali cations. I. Bacteriol. 153: 163-168.

Izaurralde, E., J. Lewis, C. McGuigan, M. Jankowska, E. Darzynkiewicz, and I.W. Mattaj. 1994. A nuclear cap binding protein complex involved in pre-mRNA splicing. Cell 78: 657-668.

Izaurralde, E., J. Lewis, C. Gamberi, A. Jarmolowski, C. McGuigan, and I.W. Mattaj. 1995. A cap-binding protein complex mediating U snRNA export. Nature 376: 709-712.

Jacquier, A., J.R. Rodriguez, and M. Rosbash. 1985. A quantitative analysis of the effects of $5^{\prime}$ junction and TACTAAC box mutants and mutant combinations on yeast mRNA splicing. Cell 43: 423-430.
Karin, M., R. Najarian, A. Haslinger, P. Valenzuela, J. Welch, and S. Fogel. 1984. Primary structure and transcription of an amplified genetic locus: The CUPl locus of yeast. Proc. Natl. Acad. Sci. 81: 337-341

Kataoka, N., M. Ohno, I. Moda, and Y. Shimura. 1995. Identification of the factors that interact with NCBP, an $80 \mathrm{kDa}$ nuclear cap binding protein. Nucleic Acids Res. 23: 36383641.

Konarska, M., R. Padgett, and P. Sharp. 1984. Recognition of cap structure in splicing in vitro of mRNA precursors. Cell 38: $731-736$.

Legrain, P. and M. Rosbash. 1989. Some cis- and trans-acting mutants for splicing target pre-mRNA to the cytoplasm. Cell 57: 573-583.

Legrain, P., B. Séraphin, and M. Rosbash. 1988. Early commitment of yeast pre-mRNA to the spliceosome pathway. Mol. Cell. Biol. 8: 3755-3760.

Legrain, P., C. Chapon, E. Schwob, R. Martin, M. Rosbash, and B. Dujon. 1991. Cloning of the two essential yeast genes, PRP6 and PRP9, and their rapid mapping, disruption and partial sequencing using a linker insertion strategy. Mol. \& Gen. Genet. 225: 199-202.

Lesser, C.F. and C. Guthrie. 1993. Mutational analysis of premRNA splicing in Saccharomyces cerevisiae using a sensitive new reporter gene, CUP1. Genetics 133: 851-863.

Lewis, J.D., E. Izaurralde, A. Jarmolowski, C. McGuigan, and I.W. Mattaj. 1996. A nuclear cap-binding complex facilitates association of U1 snRNP with the cap-proximal $5^{\prime}$ splice site. Genes \& Dev. (this issue).

Liao, X.C., H.V. Colot, Y. Wang, and M. Rosbash. 1992. Requirements for U2 snRNP addition to yeast pre-mRNA. Nucleic Acids Res. 20: 4237-4245.

Liao, X.C., J. Tang, and M. Rosbash. 1993. An enhancer screen identifies a gene that encodes the yeast Ul snRNP A protein: Implications for snRNP protein function in pre-mRNA splicing. Genes \& Dev. 7: 419-428.

Michaud, S. and R. Reed. 1991. An ATP-independent complex commits pre-mRNA to the mammalian spliceosome assembly pathway. Genes \& Dev. 5: 2534-2546.

Moore, M.J., Query, C.C., and P.A. Sharp. 1993. Splicing of precursors to mRNAs by the spliceosome. In The RNA world (ed. R.F. Gesteland and J.F. Atkins), pp. 303-357. Cold Spring Harbor Laboratory Press, Cold Spring Harbor, NY.

Newman, A.J., R.-J. Lin, S. Cheng, and J. Abelson. 1985. Molecular consequences of specific intron mutations on yeast mRNA splicing in vivo and in vitro. Cell 42: 335-344.

Pikielny, C.W. and M. Rosbash. 1985. mRNA splicing efficiency in yeast and the contribution of nonconserved sequences. Cell 41: 119-126.

Rasmussen, E. and J. Lis. 1993. In vivo transcriptional pausing and cap formation on three Drosophila heat shock genes. Proc. Natl. Acad. Sci. 90: 7923-7927.

Rosbash, M. and B. Séraphin. 1991. Who's on first? The U1 snRNP-5' splice site interaction and splicing. Trends Biochem. Sci. 16: 187-190.

Ruden, D.M., J. Ma, Y. Li, K. Wood, and M. Ptashne. 1991. Generating yeast transcriptional activators containing no yeast protein sequences. Nature 350: 250-252.

Rymond, B.C. and M. Rosbash. 1992. Yeast pre-mRNA splicing. In The molecular and cellular biology of the yeast Saccharomyces cerevisiae: Gene expression (ed. E.W. Jones, J.R. Pringle, and J.R. Broach), pp. 143-192. Cold Spring Harbor Laboratory Press, Cold Spring Harbor, NY.

Schwer, B. and S. Shuman. 1996. Conditional inactivation of mRNA capping enzyme affects yeast mRNA splicing in vivo. RNA (in press). 
Colot et al.

Séraphin, B. and M. Rosbash. 1989. Identification of functional Ul snRNA-pre-mRNA complexes committed to spliceosome assembly and splicing. Cell 59: 349-358.

1991. The yeast branchpoint sequence is not required for the formation of a stable Ul snRNP-pre-mRNA complex and is recognized in the absence of U2 snRNA. EMBO $I$. 10: $1209-1216$.

Steitz, J.A. 1992. Splicing takes a Holliday. Science 257: 888889.

Stutz, F. and M. Rosbash. 1994. A functional interaction between Rev and yeast pre-mRNA is related to splicing complex formation. EMBO J. 13: 4096-4104.

Stutz, F., M. Neville, and M. Rosbash. 1995. Identification of a novel nuclear pore-associated protein as a functional target of the HIV-1 Rev protein in yeast. Cell 82: 495-506.

Teem, J.L. and M. Rosbash. 1983. Expression of a $\beta$-galactosidase gene containing the ribosomal protein 51 intron is sensitive to the rna2 mutation of yeast. Proc. Natl. Acad. Sci. 80: $4403-4407$.

Uemura, H. and Y. Jigami. 1992. GCR3 encodes an acidic protein that is required for expression of glycolytic genes in Saccharomyces cerevisiae. I. Bacteriol. 174: 5526-5532.

Umen, J.G. and C. Guthrie. 1995. A novel role for a U5 snRNP protein in 3' splice site selection. Genes \& Dev. 9: 855-868.

Zamore, P.D., J.G. Patton, and M.R. Green. 1992. Cloning and domain structure of the mammalian splicing factor U2AF. Nature 355: 609-614. 


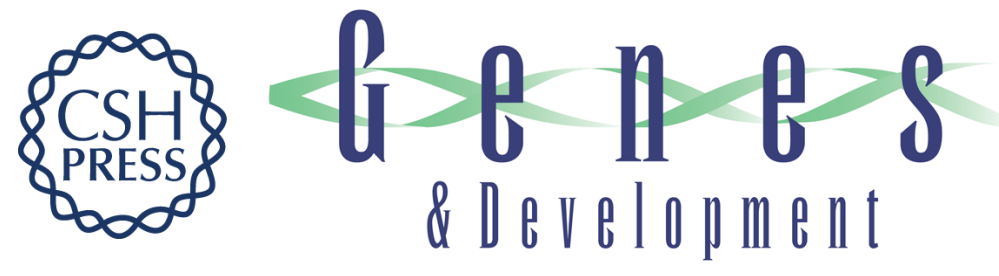

\section{The yeast splicing factor Mud13p is a commitment complex component and corresponds to CBP20, the small subunit of the nuclear cap-binding complex.}

H V Colot, F Stutz and M Rosbash

Genes Dev. 1996, 10:

Access the most recent version at doi:10.1101/gad.10.13.1699

References This article cites 34 articles, 14 of which can be accessed free at:

http://genesdev.cshlp.org/content/10/13/1699.full.html\#ref-list-1

License

Email Alerting Receive free email alerts when new articles cite this article - sign up in the box at the top Service right corner of the article or click here.

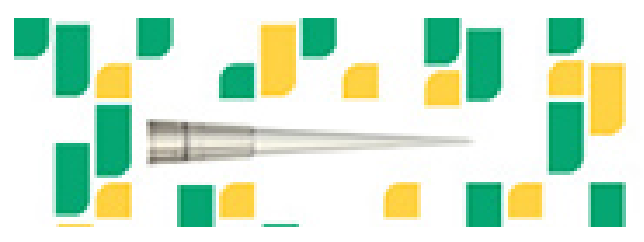

Focused on your science. 